\title{
Phylogenetic Relationships between the Western Aster Yellows Mycoplasmalike Organism and Other Prokaryotes Established by 16S rRNA Gene Sequence
}

\author{
CHERYL R. KUSKE† AND BRUCE C. KIRKPATRICK* \\ Department of Plant Pathology, University of California, Davis, California 95616
}

\begin{abstract}
Restriction fragments containing the 16S rRNA gene of the western aster yellows mycoplasmalike organism (SAY-MLO) were identified in Southern blots probed with cloned fragments of the western X-disease mycoplasmalike organism 16S rRNA gene. Two fragments which contained the entire SAY-MLO 16S rRNA gene and flanking DNA were cloned in M13 and sequenced. The SAY-MLO 16S rRNA gene is approximately $1,535 \mathrm{bp}$ long, has a $\mathrm{G}+\mathrm{C}$ content of $47 \mathrm{~mol} \%$, and has an overall secondary structure similar to that proposed for Escherichia coli. Putative rRNA promoter sequences and sequences involved in processing of the primary rRNA transcript were similar in the SAY-MLO, two Mycoplasma species, and Bacillus subtilis, suggesting that these prokaryotes and the mycoplasmalike organisms may have similar transcriptional and processing enzymes. We identified two tRNA genes, a tRNA ${ }^{\text {Tyr }}$ (GTA) gene upstream from the 16S rRNA gene and a tRNA ${ }^{\text {Ile }}$ (GAT) gene in the spacer region between the 16S and 23S rRNA genes. Comparisons of the SAY-MLO 16S rRNA nucleotide sequence with 16S rRNA sequences of other organisms indicated that the SAY-MLO is phylogenetically related most closely to other plant-pathogenic mycoplasmalike organisms, followed by Anaeroplasma species, Acholeplasma species, and some Mycoplasma species.
\end{abstract}

One approach to examining phylogenetic relationships among the prokaryotes is based on nucleotide sequence comparisons of the evolutionarily conserved $5 \mathrm{~S}$ and $16 \mathrm{~S}$ rRNA genes $(5,10,15,30,36,40,43,54,55,58)$. The $16 \mathrm{~S}$ rRNA gene is a particularly valuable evolutionary marker because it is larger and its rRNA has a more complex secondary structure than the 5S rRNA gene. Because of its central role in cell metabolism, the prokaryote 16S rRNA gene is highly conserved across widely divergent taxa, which frequently exhibit at least $70 \%$ sequence homology in this gene.

Initially, oligonucleotide catalogs of $16 \mathrm{~S}$ rRNA sequences were used to make phylogenetic comparisons between prokaryotes $(10,57,58)$. Comparative analyses of full-length $16 \mathrm{~S}$ rRNA genes have allowed an even more detailed evaluation of phylogenetic relationships among microorganisms. Evolutionary distances between organisms are calculated on the basis of the presence and number of base pair matches, mismatches, and gaps in the compared sequences. Distance matrix $(9,36,54)$ and maximum parsimony $(25,36,54)$ analyses have been used to generate phylogenetic trees from aligned 16S rRNA sequences.

The plant-pathogenic mycoplasmalike organisms (MLOs) have not yet been cultured in vitro or isolated in pure form from their plant or insect hosts. For this reason, very little is known about the physiology or genetics of these organisms. Plant-pathogenic MLOs and culturable mycoplasmas are morphologically similar and are susceptible to similar antibiotics (17). However, the definitive classification of these organisms as Mollicutes must be based on genetic data. The objectives of this study were (i) to clone and sequence the 16S rRNA gene from the severe strain of the western aster yellows MLO (SAY-MLO) in order to characterize the basic

\footnotetext{
* Corresponding author.

$\dagger$ Present address: Genomics and Structural Biology Group, Life Sciences Division, Los Alamos National Laboratory, Los Alamos, NM 87545.
}

structure of an MLO gene and its regulatory sequences and (ii) to use the $16 \mathrm{~S}$ rRNA sequence to establish phylogenetic relationships between the SAY-MLO and other prokaryotes.

\section{MATERIALS AND METHODS}

General procedures. Unless otherwise noted, the procedures used in this study were adapted from standard molecular biological protocols $(2,29)$. The buffers and reaction conditions used for restriction enzymes, calf intestinal alkaline phosphatase (Bochringer Mannheim), exonuclease III (ExoIII) (Bethesda Research Laboratories), the Klenow enzyme (New England Biolabs), T4 DNA ligase (New England BioLabs), and Sequenase (Amersham) were those suggested by the manufacturers.

DNA extractions. DNAs were isolated from healthy celery (Apium graveolens) plants and celery plants that were inoculated with the SAY-MLO (11) by using infectious Macrosteles severini leafhoppers. Symptomatic leaves and apical tissues were ground in buffer, and an MLO-enriched fraction was obtained by differential centrifugation. DNA was extracted from this fraction as previously described (24).

X-MLO 16S rRNA gene probes. Cloned fragments of the western X-disease MLO (X-MLO) 16S rRNA gene were used as probes to identify the SAY-MLO 16S rRNA gene in Southern blot hybridizations. A 1.9-kb HindIII-EcoRI fragment (fragment PY6) contained approximately 670 bp of the $5^{\prime}$ region of the X-MLO $16 \mathrm{~S}$ rRNA gene and about $1.2 \mathrm{~kb}$ of upstream sequences (18). An EcoRI-BamHI fragment (fragment WXR187) contained 796 bp of the $3^{\prime}$ region of the X-MLO 16S rRNA gene. X-MLO 16S rRNA sequences were excised from the cloning vectors by using the appropriate restriction enzymes, electrophoresed in 1\% Seakem GTG agarose (FMC Bioproducts) gels, and electroeluted from the gels by using an Elutrap chamber (Schleicher \& Schuell). The 1.9-kb and 796-bp fragments of the X-MLO 16S rRNA gene are referred to below as the $5^{\prime}$ and $3^{\prime}$ probes, respectively. The probes were radioactively labeled with $\left[\alpha-{ }^{32} \mathrm{P}\right] \mathrm{dATP}$ by using random oligoprimers (Multiprime kit; 
Amersham). In addition, an oligonucleotide was synthesized from an 18-bp sequence of the $5^{\prime}$ region that is conserved in mycoplasma 16S rRNA genes but absent from plant chloroplast 16S rRNA genes (19). The 5' 18-mer was end labeled with $\left[\gamma-{ }^{32} \mathrm{P}\right]$ ATP by using T4 polynucleotide kinase.

Southern blot analysis of the SAY-MLO 16S rRNA gene. DNAs from SAY-MLO-infected and healthy celery plants were purified by using DEAE columns (Elutip-d; Schleicher \& Schuell), digested with EcoRI, HindIII, XbaI, HincII, $B s t \mathrm{NI}$, or combinations of two enzymes, and electrophoresed in $1 \%$ agarose gels. The DNAs were transferred to nylon membranes (Nytran; Schleicher \& Schuell) and hybridized with either the $5^{\prime}$ or the $3^{\prime}$ X-MLO rRNA probe described above.

Hybridization conditions. Prehybridization and hybridization were carried out in solutions containing $50 \%$ formamide (21), and posthybridization washes were of moderate stringency (24).

Cloning the SAY-MLO 16S rRNA gene. The $5^{\prime}$ probe hybridized with two EcoRI fragments $(2.5$ and $1.0 \mathrm{~kb})$ that were present in DNA isolated from SAY-MLO-infected plants but not in DNA isolated from healthy plants. The $3^{\prime}$ probe hybridized with one SAY-MLO-specific EcoRI fragment which was $6.7 \mathrm{~kb}$ long. This $6.7-\mathrm{kb}$ fragment was digested with HindIII, and a 1.5-kb EcoRI-HindIII subfragment then specifically hybridized with the $3^{\prime}$ probe. DNA from SAY-MLO-infected celery plants was digested with restriction enzymes and electrophoresed in 1\% Seakem GTG agarose gels. Regions of EcoRI-digested SAY-MLO DNA containing fragments that were 2.8 to 1.1 and 1.3 to $0.9 \mathrm{~kb}$ long and EcoRI-HindIII fragments that were between 1.7 and $1.0 \mathrm{~kb}$ long were electroeluted from the gels and were purified by using DEAE columns.

The EcoRI fragments were ligated into the replicative form of EcoRI-digested, dephosphorylated M13mp18. The EcoRI-HindIII fragments were ligated into similarly digested M13mp19. Ligated molecules were transformed in competent Escherichia coli LL308 cells. Cells from each transformation reaction were suspended in top agarose that overlaid Luria broth agar. White (recombinant), turbid plaques were transferred onto nitrocellulose filters and lysed in sodium dodecyl sulfate, and the DNA was bound to the filters by alkaline hydrolysis and baking.

Nitrocellulose filters containing recombinant phage generated from the $E c o$ RI fragment transformation were hybridized with the 5' 18-mer. After clones that hybridized with the 18 -mer were identified, the bound probe was removed by boiling the filters in $0.01 \%$ SSPE (SSPE is $0.15 \mathrm{M} \mathrm{NaCl}, 10$ $\mathrm{mM} \mathrm{NaPO}$, and $1 \mathrm{mM}$ EDTA [pH 7.7]) containing $0.5 \%$ sodium dodecyl sulfate, and this was followed by a rinse in $2 \times \mathrm{SSC}(1 \times \mathrm{SSC}$ is $0.15 \mathrm{M} \mathrm{NaCl}$ plus $0.015 \mathrm{M}$ sodium citrate). Stripped filters were exposed to X-ray film to ensure removal of the probe. The filters were then hybridized with the X-MLO 5' probe. Filters which contained recombinant phage containing EcoRI-HindIII fragments were hybridized with the $3^{\prime}$ probe in a similar manner. Plaques that hybridized were transferred, purified, and screened a second time. The replicative forms of recombinant phage were isolated and digested with restriction enzymes to excise the cloned fragments from the vector DNA. Digested DNAs from recombinant plasmids and size-fractionated, SAY-MLOenriched DNA were separated by electrophoresis in an agarose gel, transferred to a nylon membrane, and probed with the $5^{\prime}$ or $3^{\prime}$ X-MLO probe to verify the identity of the cloned SAY-MLO 16S rRNA fragments.

The cloned SAY-MLO 2.5-kb EcoRI and 1.5-kb EcoRI-
HindIII fragments were gel purified as described above and subcloned in both orientations into M13mp19. The ends of the 1.5-kb EcoRI-HindIII fragment were filled in by using the Klenow enzyme and blunt end ligated into the SmaI site of M13mp19. The 2.5-kb EcoRI fragment was subcloned into the EcoRI site of the same vector. The presence of both orientations of each cloned fragment was determined by using the $\mathrm{C}$ test.

Nested deletions were made in each of the four subclones by subjecting them to ExoIII digestion (14). Religated, deletion clones were transformed in $E$. coli LL308, and replicative and template forms were isolated. Clones having overlapping, consecutive, 100 - to 200-bp deletions were selected and sequenced.

Sequencing the SAY-MLO rRNA gene. Single-stranded, recombinant M13 templates were precipitated from the supernatants of infected strain LL308 cells by using $25 \%$ polyethylene glycol-2.5 M NaCl (14). Approximately $300 \mathrm{bp}$ of each template was sequenced by the dideoxy method, using ${ }^{35}$ S-labeled dATP (Sequenase kit; Amersham) and the protocols suggested by the manufacturer. Sequencing reaction mixtures were electrophoresed in $7 \%$ acrylamide, buffer gradient gels (3), fixed in $10 \%$ acetic acid-methanol, vacuum dried for $2 \mathrm{~h}$ at $80^{\circ} \mathrm{C}$, and exposed to $\mathrm{X}$-ray film at room temperature. The two strands of the two cloned SAY-MLO 16S rRNA fragments were sequenced separately. Approximately $3 \mathrm{~kb}$ of the cloned SAY-MLO DNA was sequenced.

Sequence analysis and phylogenetic relationships. The sequences of overlapping clones were compiled by using Microgenie software (Beckman Instruments). Alignments and comparisons with 16S rRNA sequences of other organisms were made by using the Genetics Computer Group sequencing analysis software package (6).

Pairwise evolutionary distances were computed from the percentages of similarity of aligned sequences, and dendrograms were constructed from evolutionary distance matrices as described by Weisberg et al. (54).

Nucleotide sequence accession number. The nucleotide sequnce of the SAY-MLO 16S rRNA gene and the flanking regions shown in Fig. 2 have been deposited in GenBank under accession number M86340.

\section{RESULTS AND DISCUSSION}

Identification of the SAY-MLO 16S rRNA gene. Southern blots of EcoRI-digested DNAs from healthy and SAY-MLOinfected celery plants that were hybridized with the X-MLO 16S rRNA probes contained SAY-MLO-specific DNA fragments, as well as fragments common to both MLO-infected and healthy celery (Fig. 1). The common fragments were presumed to be the celery chloroplast $16 \mathrm{~S}$ rRNA gene.

When blots were probed with the 5' X-MLO probe, two MLO-specific bands, which were 2.5 and $1.0 \mathrm{~kb}$ long, were present (Fig. 1A). These same two fragments also hybridized with the X-MLO 18-mer (data not shown). However, only one SAY-MLO-specific hybridization band $(6.7 \mathrm{~kb})$ was present in EcoRI Southern blots that were probed with the X-MLO 3' probe (Fig. 1B). A 1.5-kb EcoRI-HindIII band was observed in SAY-MLO-infected celery DNA that was probed with the X-MLO $3^{\prime}$ probe, but this band was not present in healthy celery DNA treated in the same way (data not shown).

The hybridization results obtained with the $5^{\prime} \mathrm{X}-\mathrm{MLO}$ and the 18-mer oligonucleotide probes suggest that the SAYMLO may contain two 16S rRNA genes. If the SAY-MLO has two copies of the 16S rRNA gene, the HindIII sites at the 


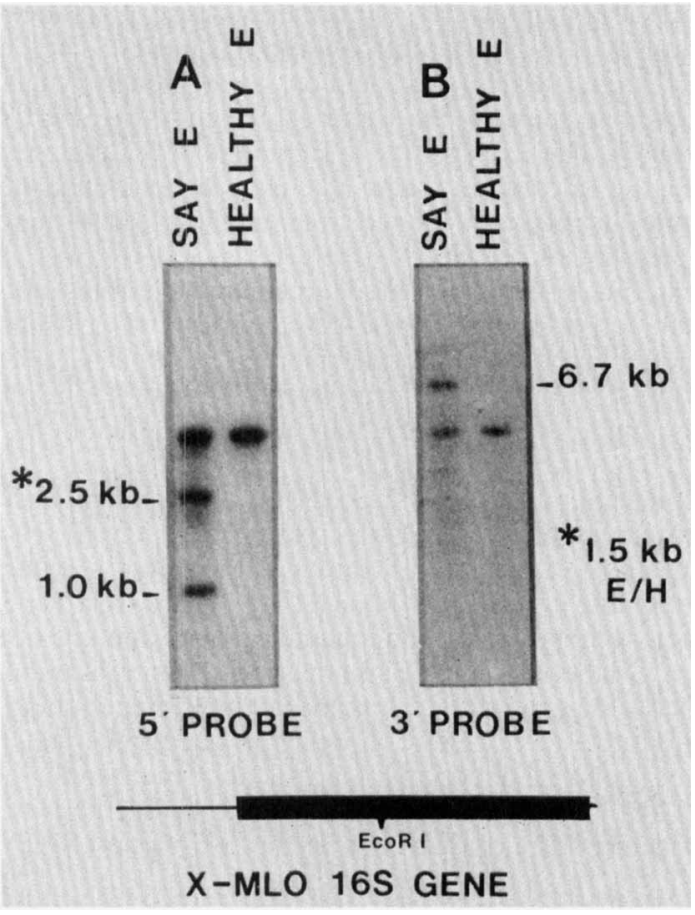

FIG. 1. Southern blot hybridization of EcoRI-digested (E) DNAs extracted from celery infected with SAY-MLO (SAY) and healthy celery and probed with cloned fragments of the $5^{\prime}$ and $3^{\prime}$ regions of the X-MLO 16S rRNA gene. Two MLO-specific bands hybridized with the $5^{\prime} X-M L O$ probe (A), and one unique band hybridized with the $3^{\prime}$ X-MLO probe (B). E/H, DNA digested with EcoRI plus HindIII. The asterisk indicates the size and type of restriction fragments that contained the SAY-MLO 16S rRNA gene that was cloned and sequenced in this study.

$3^{\prime}$ ends of both the $6.7-\mathrm{kb}$ fragment and the $1.5-\mathrm{kb}$ fragment, would have to lie in highly conserved regions downstream from each of the two 16S rRNA gene copies, so that the fragments generated from both copies would be identical in size. The HindIII site of the $1.5-\mathrm{kb}$ fragment is indeed a conserved restriction site in the $5^{\prime}$ region of $23 \mathrm{~S}$ rRNA gene. Additional restriction and sequence analyses will be necessary to conclusively determine whether the SAY-MLO possesses more than one copy of the 16S rRNA gene.

In contrast to most bacteria, which typically have 8 to 10 rRNA operons, the presence of only one or two rRNA operons is common among the members of the Mollicutes (1, 39). The acholeplasmas have two rRNA operons, while the spiroplasmas and mycoplasmas have either one or two copies $(1,4)$. The small number of rRNA operons in the Mollicutes is not unusual considering that the sizes of the genomes of these organisms are one-fourth to one-eighth the sizes of most bacterial genomes $(4,39,41)$. The presence of one or two rRNA operons in the SAY-MLO suggests that this organism shares this property with culturable Mollicutes species.

Structural characteristics of the SAY-MLO 16S rRNA gene sequence. The regions of the SAY-MLO sequence that code for rRNA and tRNA genes were identified by sequence homology and alignment with similar genes of other prokaryotes. Although the length of the 16S rRNA gene was estimated to within a few base pairs, we have no transcriptional or direct rRNA sequence data to verify the actual beginning and ending nucleotides. The region of the SAY-
MLO that was sequenced contains (i) 953 bp (553 bp shown in Fig. 2) upstream from the 16S rRNA gene, (ii) the entire 16S rRNA gene (approximately 1,535 bp long), (iii) $243 \mathrm{bp}$ between the $16 \mathrm{~S}$ and $23 \mathrm{~S}$ rRNA genes, and (iv) $293 \mathrm{bp}$ of the 5 ' region of the $23 \mathrm{~S}$ rRNA gene (Fig. 2). The length of the SAY-MLO 16S rRNA gene is within the range that is typical for prokaryotic organisms (about $1,540 \mathrm{bp}$ ), but differs from the length of plant chloroplast 16S rRNA genes (about 1,500 bp) $(5,34)$. The SAY-MLO $16 \mathrm{~S}$ rRNA gene contains at its $3^{\prime}$ terminus the following conserved sequence: GATCA CCTCCTTTCT (Fig. 2). This region of the 16S rRNA binds to mRNAs (48) and is involved in the formation of the complex between mRNA and the $30 \mathrm{~S}$ ribosomal subunit to initiate translation. The SAY-MLO 3 '-terminal sequence is identical to that of Mycoplasma capricolum and Bacillus subtilis and differs from the $E$. coli $3^{\prime}$-terminal sequence, in which the terminal nucleotides TCT are replaced by a single adenosine residue.

There is an EcoRI site about $670 \mathrm{bp}$ from the $5^{\prime}$ end of the SAY-MLO 16S rRNA gene. This EcoRI site is also present in the 16S rRNA genes of the X-MLO, an MLO that infects Oenothera spp. (O-MLO) (25), and many other mollicutes and bacteria $(5,39)$. A Pst I site that is often present just downstream from the EcoRI site in many acholeplasma, spiroplasma, and mycoplasma $16 \mathrm{~S}$ rRNA genes (4) is not present in the SAY-MLO 16S rRNA sequence.

Most prokaryote 16S rRNA genes are transcribed as an operon which contains both rRNA and tRNA genes. The rRNA gene order, 5'-16S-23S-5S-3', is typical of bacterial rRNA operons, and the rRNA operons of most Mycoplasma species also exhibit this organizational pattern $(4,12,39,46)$. However, in the Mycoplasma hyopneumoniae rRNA operon the closely spaced $16 \mathrm{~S}$ and $23 \mathrm{~S}$ rRNA genes are separated from the 5S rRNA gene, which is more than $4 \mathrm{~kb}$ downstream (52). In the SAY-MLO rRNA operon, the 23S rRNA gene follows the 16S rRNA gene, and the two are separated by an AT-rich spacer region which is about $243 \mathrm{bp}$ long. The 6.7-kb EcoRI fragment from the SAY-MLO (Fig. 1) contains the remainder of the SAY-MLO 23S rRNA and possibly the $5 S$ rRNA gene.

The guanine-plus-cytosine $(\mathrm{G}+\mathrm{C})$ contents of the coding and noncoding regions in the cloned SAY-MLO fragments vary considerably. The $\mathrm{G}+\mathrm{C}$ content of the noncoding region upstream from the $16 \mathrm{~S}$ rRNA gene is only $25 \mathrm{~mol} \%$. This value suggests that the average $G+C$ content of the SAY-MLO, like the $\mathrm{G}+\mathrm{C}$ contents of the culturable mollicutes $(4,39)$ and other MLOs $(22,47)$, is probably less than $30 \mathrm{~mol} \%$. The $\mathrm{G}+\mathrm{C}$ content of the SAY-MLO $16 \mathrm{~S}$ rRNA gene is $47 \mathrm{~mol} \%$, a value that is similar to the values for other mollicutes $(16,18,25)$ and considerably less than the values for eubacteria, such as $B$. subtilis and $E$. coli, which are 55 mol\% (5).

The SAY-MLO 16S rRNA gene sequence could be superimposed on the secondary structure of the $E$. coli $16 \mathrm{~S}$ rRNA gene $(5,34,54,56)$ with little overall structural alteration. In most cases base pair changes were complementary, so the secondary structures of conserved regions were maintained. For example, $G$. C pairs were often replaced with $G$. U or A . U pairs, reflecting the lower $\mathrm{G}+\mathrm{C}$ content of the SAYMLO gene. Major gaps and base pair changes were clustered within eight variable regions $(5,23)$. Possible secondary structures of the variable regions were drawn for the SAYMLO, Mycoplasma capricolum, B. subtilis, and E. coli (representing the MLOs, culturable mycoplasmas, grampositive bacteria, and gram-negative bacteria, respectively) (23). In variable region V2, the structure of the SAY-MLO 
1 TTCCTTCATC AatactTgCa ACAATTCAAA AatcaAaAta AgtaAaAaAC

51 AAACAAAACT TTTATATTTT TTTCTGCATT TCTTAATTTT CATCCTTATA

101 ATTTTTAAAA AACATCTTTT GGAAAGCAAC ATATTTAGTT AGGATAATTT

151 CTTCATAAA ${ }^{-10}$ ATATTTTTTA TTTTGCAAAA AAAATATTTC AAACACCATT

201 ATCCAATTCC AAAATATCTT TTTCCAAACC CCAAATTCCT ATCAAAAATA

251 ACAACCTAAA TTAAAATTTA AAAAAAATCA AAAAAGCTIG CTTTPCATTT

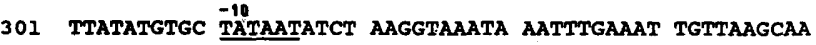

351 TTTCGGAGGG ATAGCGAAGT GGCTAAACGC AGCAGTCTGT AAAACTGTTC

402 CGTAAGGTAC GGTGGTTCGA ATCCACCTCC CTTCACCATT STEM

451 aTCTTIGAA ACTGAAGATG ATAATTAACG AATATTTTTA ATTATTTTTT

501 AACACCTTAA AATTGACACC AAAAAGCAAT TTTTGATGTA TCAATTTTGT 165 rRNA start

551 AACATACGAA GAGTTTGATC CTGGCTCAGG ATTAACGCTG GCGGCGTGCC

601 TAATACATGC AAgTCGAACg GAAGTTTAAg CAATTAAACT TTAGTGGCGA

651 ACGGGTGAGT AACGCGTAAG CAATCTGCCC CTAAGACGAG GATAACAGTT

701 GGAAACGACT GCTAAGACTG GATAGGAGAC AAGAGGGCAT CTTCTTGTTT

751 TTAAAAGCC TAgCAATAGg TATGCTTAGg GAgGAgCTTG CGTCACATTA

801 GTTAGITGGT GGGGTAAGG CCTAACAAGA CTATGATGTG TAGCCGGGCT

851 GAGAGgTtGa ACGGCCACAT TGgGACTGAG ACACGGCCCA AACTCCTACG

901 GgAGgCAGCA GTAGGgAaTT TTCGgCAATG GAGGAAACTC TGACCGAGCA

951 ACGCCGCGTG AACGATGAAG TATTTCGGTA CGTAAAGTTC TTTTATTAGG

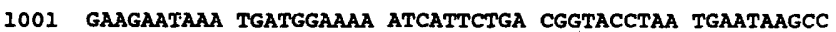

1051 CCGgCTAACT ATGTGCCAGC AGCCGCGgTA ATACATAGgG GgCAagCGTT

1101 ATCCGgATT ATTGGGCGTA AAGgGTGCGT AGGCGGTTAA ATAAGTTTAT

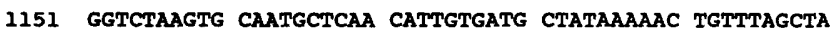

1201 GAGTAAGATA GAGGCAAGTG GAATCCATG TGTAGTGGTA AAATGCGTAA

1251 ATATATGGAG GAACACCAGT AGCGAAGGCG GCTTGCTGGG TCTTTACTGA
1301 CGCTGAGgCA CGAAAGCGTG GgGagcaAAC AGgATTAGAT ACCCTGGTAG

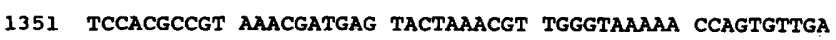

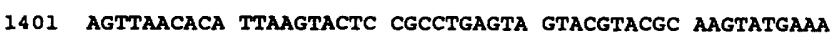

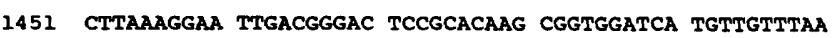

1501 TTCGAAgGTA CCCGAAAAAC CTCACCAGgT CTTGACATGC TTCTGCAAAG

1551 CTGTAGAAAC ACAGTgGagg TMATCAGTTG CACAGGTGGT GCATGGTTGT

1601 CGTCAGCTCG TGTCGTGAGA TGTTGGGTTA AGTCCCGCAA CGAGCGCAAC

1651 CCTTATTGT AGTTACCAGC ACGTAATGGT GGGGACTTTA GCAAGACTGC

1701 CAGTGATAAA TTGgAGgAag GTGgGGACGA CGTCAAATCA TCATGCCCCT

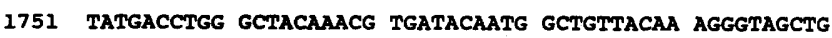

1801 AAGCGCAAGT TTTTGGCGAA TCTCAAAAAA ACAGTCTCAG TTCGgATTGA

1851 AGTCTGCAAC TCGACTTCAT GAAGTTGGAA TCGCTAGTAA TCGCGAATCA

1901 GCATGTCGCG GTGAATACGT TCTCGGGGTT TGTACACACC GCCCGTCAAA

1951 CCACGAAAGT TGGTAATACC CAAAGCCGGT GGCCTAACTT CGCAAGAAGA

2001 GGGACCGTC TAAGGTAGG TCGATGATTG GGGTTAAGTC GTAACAAGGT

2051 ATCCCTACCG GAAGGTGGG ATGGATCACC TCCTTTCTAA GGAAACAATT

2101 ATCATCTTCA GTITTGAGAG ACTTAAGAA GTTTTTCATT GTAACTTGCT

2151 TGCAAATTGT ATITGCAACA TTTTAATCTT TITAAGATTA AGGGCCTATA

2201 GCTCAGTTGG TTAGAGCACA CGCCTGATAA GCGTGAGGTC GGTGGTTCAA

2251 GTCGATHTAG GCCCACCATA ACCACAAATA GGCAAAATCT TAAAAAAGCT

2301 CTTTTGAAAAg TAGATAAACG AAGGTTAAAA AATCAAAGGA ACTAAGGGCG

2351 CACAGTGGAT GCCTTGGCAC TAAGAGCCGA TGAAGgACGC AATTAACGGC

2401 GAAACGCCAC GGGAAGTGT AAATAAGTGA AGATCCGTGG GTCTCCGAAT

2451 GGGAAACCC ATTACATTGA AGATGTAATA TTCTTCTAAT GCGATTTATC

2501 TtgtTagaAg aAaggaAacg cGgcGaActg aAATATCtaA gTAaccGcag

2551 gaAagaAag taAtaAcga cccGgäag cctgatacca tTtctagtTa

2601 CAAAATTTTA ACGAAGTAGA AGCT

FIG. 2. Sequence of the SAY-MLO $16 \mathrm{~S}$ rRNA gene and flanking regions. The underlined sequences are the -35 and -10 consensus sequences of two possible promoters. Nucleotides 355 through 438 encode a tRNA ${ }^{\text {Tyr }}$ (GTA) gene. Nucleotides 2192 through 2268 encode a tRNA $^{\text {Ile }}$ (GAT) gene. On the basis of comparisons with other 16S sequences, the SAY-MLO 16S rRNA structural gene begins at approximately nucleotide 554 and ends at nucleotide 2088. A 34-bp inverted repeat can form a stem by base pairing between nucleotides 441 through 475 and 2099 through 2133 (see Fig. 6). Another stem-loop structure can be produced in the inverted repeat sequence located immediately upstream from the 16S structural gene (bases 508 through 549). The conserved EcoRI site in the 16S rRNA gene begins at base 1221. The sequence that codes for 16S rRNA sequences that bind with mRNA Shine-Dalgarno sequences is located at bases 2079 through 2084.

was more similar to the structure of mycoplasmas and gram-positive bacteria than to the structure of gram-negative bacteria. In other variable regions, for example regions V8 and $\mathrm{V} 9$, the secondary structure of the SAY-MLO gene did not resemble the structure of one group more than the structure of another, and the structure was unique to the MLO. In three of the regions (regions V1, V5, and V7) the SAY-MLO structure appeared to be intermediate between the E. coli and Mycoplasma capricolum extremes.

SAY-MLO tRNAs. Two SAY-MLO tRNA genes were identified in the sequenced region. An 84-bp tRNA ${ }^{\mathrm{Tyr}}$ (GTA) gene is present upstream from the $16 \mathrm{~S}$ rRNA gene, and a 77-bp tRNA ${ }^{\text {Ile }}$ (GAT) gene is located in the spacer region between the 16S and 23S rRNA genes (Fig. 2 and 3). The $16 \mathrm{~S}$ rRNA operons of the X-MLO and the O-MLO also have a tRNA $^{\text {Ile }}$ gene in the $16 \mathrm{~S}-23 \mathrm{~S}$ rRNA spacer region $(20,25)$, but neither of these MLOs has a tRNA gene upstream from the $16 \mathrm{~S}$ rRNA gene. E. coli rRNA operons often contain a tRNA $^{\text {Ile }}$ gene followed by a tRNA ${ }^{\text {Ala }}$ gene or a single tRNA $^{\text {Glu }}$ gene in the $16 \mathrm{~S}-23 \mathrm{~S}$ rRNA spacer region $(31,59)$. Two of eight $B$. subtilis rRNA operons contain adjacent tRNA $^{\text {Ile }}$ and tRNA ${ }^{\text {Ala }}$ genes, while the other six operons do not contain tRNA genes in the spacer region $(13,26)$. However, tRNA genes of these and other bacteria do not occur $5^{\prime}$ to the 16S rRNA gene. One of the two rRNA operons of Mycoplasma capricolum contains adjacent tRNA $^{\text {Lys }}$ and tRNA ${ }^{\text {Leu }}$ genes, which are just upstream from the 16S rRNA gene (Fig. 4) $(38,51)$, but the mycoplasmas examined thus far do not have tRNA genes in the 16S-23S rRNA spacer region $(38,46,50)$. Thus, the arrangement of two tRNA genes flanking the 16S rRNA gene in the SAYMLO is unique among the prokaryotes that have been studied to date.

The SAY-MLO tRNA ${ }^{\text {Tyr }}$ gene is 81,80 , and $63 \%$ homologous to the tRNA ${ }^{\mathrm{Tyr}}$ genes of Mycoplasma capricolum, $B$. subtilis, and $E$. coli (tyr-1), respectively. The SAY-MLO tRNA ${ }^{\text {Ile }}$ gene is $100,94,87,82$, and $78 \%$ homologous to the tRNA $^{\text {Ile }}$ genes of the O-MLO, B. subtilis, E. coli, Mycoplasma mycoides, and Spiroplasma melliferum (44), respectively. Both of the SAY-MLO tRNAs can be folded into a typical tRNA secondary structure (Fig. 3). Although there are a number of nucleotide mismatches between the SAYMLO tRNAs and the corresponding tRNAs from other organisms, most of the changes are present in complemen- 


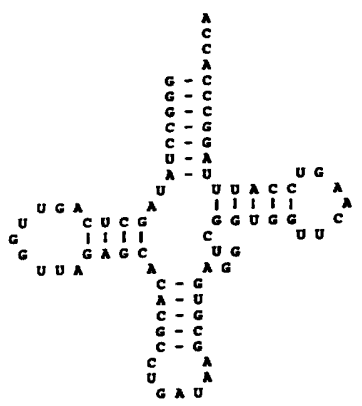

ile

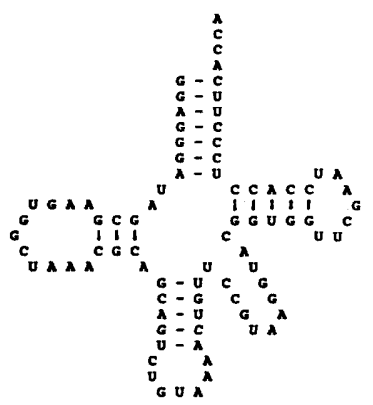

tyi
FIG. 3. Secondary structures of the two tRNAs from SAYMLO.

tary base pairs, and the secondary structure of the SAYMLO tRNAs is virtually identical to that of other mollicute and bacterial tRNAs (23).

The $\mathrm{G}+\mathrm{C}$ contents of the two SAY-MLO tRNA genes (55 and $50 \mathrm{~mol} \%$ for the tRNA ${ }^{\mathrm{Tyr}}$ and tRNA ${ }^{\text {Ile }}$ genes, respectively) are considerably higher than the $G+C$ content of the SAY-MLO noncoding region and are typical values for bacterial tRNA genes. As is the case with the 16S rRNA gene, the comparatively high $\mathrm{G}+\mathrm{C}$ contents of the SAYMLO tRNA genes are probably necessary for the formation of critical secondary structures (Fig. 3).

Putative rRNA transcription and processing sequences. Putative promoter sequences of the SAY-MLO rRNA operon were identified in the region $5^{\prime}$ to the $16 \mathrm{~S}$ rRNA structural gene on the basis of homology with the -35 and -10 RNA polymerase binding consensus sequences (Fig. 2 and 4) $(4,45)$. Dual promoters are present in the rRNA operons of some mycoplasmas $(38,50,51)$, spiroplasmas $(4)$, and bacteria $(13,35)$. Both of the Mycoplasma capricolum and $B$. subtilis promoters have been shown to be transcriptionally active $(13,50,51)$. Other than the promoter consensus sequences and the 19-bp stem region (see below), there was little sequence homology among the 16S rRNA upstream regions of the SAY-MLO, the other MLOs, and other culturable prokaryotes.

Bacterial rRNA operons are usually transcribed as a single primary RNA molecule, which then undergoes enzymatic processing at specific cleavage sites to generate the mature 16S, 23S, and 5S rRNAs and associated tRNAs. Processing is facilitated by the formation of secondary structures within the primary RNA transcript. A large stem-loop structure can be formed in the expected primary transcript of the SAYMLO sequence by base pairing between homologous 34-bp regions that occur both $5^{\prime}$ and $3^{\prime}$ of the $16 \mathrm{~S}$ rRNA structural gene (Fig. 2 and 5). Base pairing between these regions forms a large stem-loop structure, with the mature 16S rRNA completely contained in the loop. Similar stem-loop structures are constructed from the DNA sequences flanking the $16 \mathrm{~S}$ rRNAs of both mycoplasmas $(16,50,51)$ and bacteria $(27,59)$. In $E$. coli $(59)$ and $B$. subtilis $(13,27)$ the RNA processing enzyme, RNase III, cleaves the stem to release a precursor $16 \mathrm{~S}$ rRNA molecule from the primary transcript. The precursor $16 \mathrm{~S}$ rRNA is then cleaved by another enzyme at the $3^{\prime}$ end of the 16S rRNA structural gene. The $E$. coli RNase III cleavage site is located in the same region of an analogous stem-loop structure (59). However, the $E$. coli stem sequence has no homology with the $B$. subtilis sequence (Fig. 6). RNase III from B. subtilis is thought to cleave specifically at opposing, unpaired guanosine residues in the stem (27). These opposing guanosine residues are also present in the SAY-MLO stem (Fig. 6). A 19-bp sequence, which contains the RNase III cleavage site of $B$. subtilis, is highly conserved in this gram-positive bacterium, the culturable mycoplasmas, and the SAY- and X-MLOs (Fig. 5, box). The RNase III processing site in the SAY-MLO stem structure contains opposing guanosine residues similar to those of $B$. subtilis. The conservation of stem-loop formations and RNase III cleavage site sequences in the MLOs, culturable mycoplasmas, and gram-positive bacteria provides additional molecular genetic evidence of the close relationships among these prokaryotes. The sequence homologies of both the SAY-MLO putative promoters and the 16S rRNA stem-loop structures suggest that the SAY-MLO may have an RNA polymerase and other processing enzymes that are similar to those of the mycoplasmas and gram-positive bacteria.

Phylogenetic relationships. The SAY-MLO 16S rRNA sequence was most similar to the $16 \mathrm{~S}$ rRNA sequence of the O-MLO (99.6\%) (25), followed by the X-MLO sequence $(90 \%)(20)$. The SAY-MLO and the O-MLO cause similar symptoms, including virescence (greening of floral tissue) and phyllody (leaflike petals and sepals), in their host plants. In contrast, the X-MLO does not cause virescence or phyllody in plants, and it is not considered to be very closely related to the other two MLOs on the basis of biological, serological, and genetic data (17). The 16S rRNA sequences of the three MLOs are more homologous to each other than to the $16 \mathrm{~S}$ rRNA sequence of any other prokaryote. Weisberg et al. (54) characterized the phylogenetic placement of

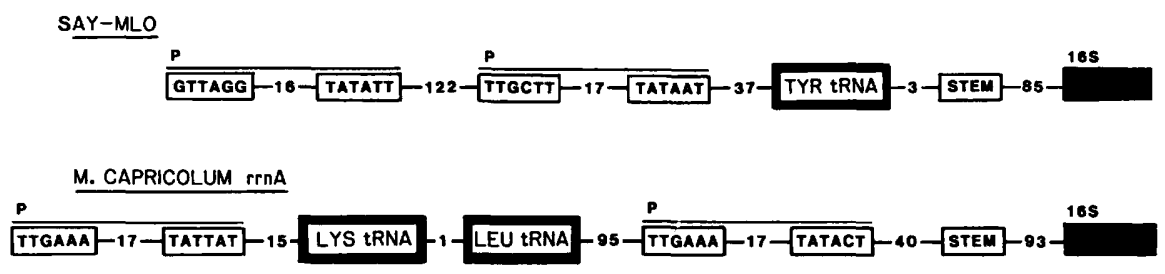

B. SUBTILIS rrnB

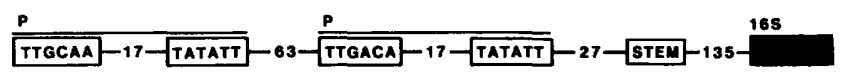

FIG. 4. Sequence comparisons of the SAY-MLO, Mycoplasma capricolum (16, 38, 51), and B. subtilis (13), showing the locations of putative rRNA promoters, tRNA genes, and the inverted repeat sequence (STEM) that could form a stem by base pairing with complementary sequences in the $16 \mathrm{~S}-23 \mathrm{~S}$ rRNA spacer region (see Fig. 5). 


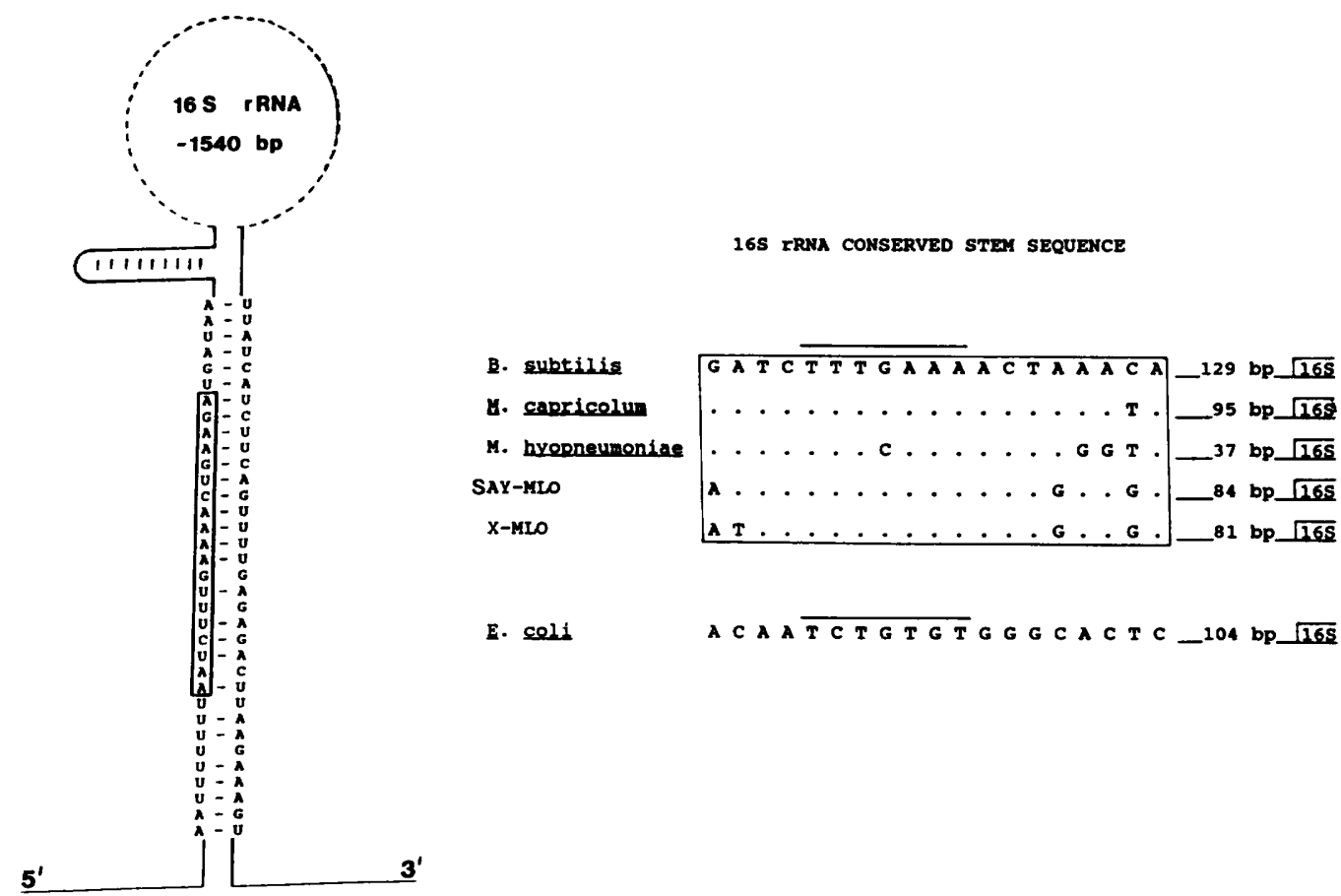

FIG. 5. Possible rRNA processing sites surrounding the SAY-MLO 16S rRNA. A 19-bp sequence spanning the RNase III cleavage site in B. subtilis (box) is highly conserved in B. subtilis $(13,27)$, Mycoplasma capricolum $(16,51)$, Mycoplasma hyopneumoniae (50), the X-MLO (20), and the SAY-MLO. The RNase III cleavage site of $E$. coli $(60)$ resides on a similar stem structure, but it has no sequence homology with the sites of the other gram-positive related organisms. The lines above the sequences indicate the RNAse III cleavage sites for $B$. subtilis and $E$. coli.

the Mollicutes and their walled relatives by using 16S rRNA sequence data. These authors proposed that the Mollicuteswalled relative clade, as well as Bacillus and Lactobacillus species, are evolutionarily derived from a gram-positive

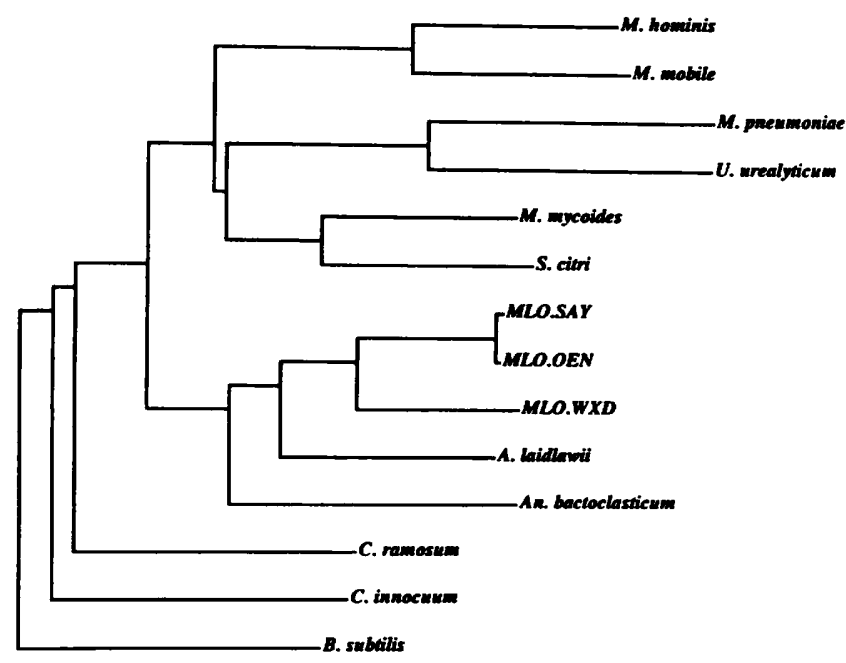

$10 \%$

FIG. 6. Phylogenetic dendrogram constructed from evolutionary distance matrices as described in the text. M., Mycoplasma; $U$., Ureaplasma; S., Spiroplasma; MLO.SAY, severe strain of the western aster yellows MLO; MLO.OEN, MLO that infects Oenothera spp.; MLO.WXD, western X-disease MLO; A., Acholeplasma; An., Anaeroplasma; C. Clostridium; B. Bacillus. clostridial ancestor. The following six subgroups or clades were defined within the Mollicutes-walled relative group: Mycoplasma pneumoniae, Mycoplasma hominis, spiroplasmas, anaeroplasmas, and asteroleplasmas, and the walled relatives. A similar analysis of the SAY-MLO 16S rRNA sequence clearly indicated that this and other MLOs are members of the anaeroplasma clade (Fig. 6), which includes Acholeplasma laidlawii and Acholeplasma modicum in addition to the Anaeroplasma species.

Estimates of MLO genome sizes by pulsed-field gel electrophoresis indicated that the MLO genomes vary in size from approximately 650 to $1,200 \mathrm{~kb}(32)$, values which are similar to the pulsed-field gel electrophoresis estimates of mycoplasma genome sizes $(33,37)$. These values are approximately one-half the values for the genomes of Acholeplasma spp., to which the MLOs are most closely related as determined by $16 \mathrm{~S}$ rRNA sequence analysis. The acholeplasmas and plant-pathogenic MLOs share some common hosts, but they differ in their physical relationships with these hosts. Acholeplasmas have been found on external plant surfaces and in the guts of certain insects (53), while plant-pathogenic MLOs are intracellular parasites of their plant and insect hosts (17).

The identification of culturable Mollicutes and bacteria which are phylogenetically related to the MLOs may facilitate further characterization of these nonculturable organisms. Transformation, transposition, and transfection have been experimentally achieved in Mycoplasma species $(7,8$, 28, 42), Acholeplasma species (8, 49), and several Bacillus species. The close phylogenetic relationship between the SAY-MLO and these culturable prokaryotes suggests that they may have potential as hosts for studying the expression and function of cloned MLO genes. In addition, many of the prokaryotes that are related to the MLOs are anaerobic or 
microaerophilic. This and other cultural characteristics of these MLO-related organisms may provide insights for culturing MLOs in vitro.

\section{ACKNOWLEDGMENTS}

We gratefully acknowledge C. R. Woese for assistance in the phylogenetic analysis and generation of the phylogenetic tree and Jeri Fraser for technical assistance.

\section{REFERENCES}

1. Amikan, D., G. Glaser, and S. Razin. 1984. Mycoplasmas (Mollicutes) have a low number of rRNA genes. J. Bacteriol. 158:376-378.

2. Ausubel, F. M., R. Brent, R. E. Kingston, D. D. Moore, J. G. Seidman, J. A. Smith, and K. Struhl (ed.). 1987. Current protocols in molecular biology. Wiley Interscience, New York.

3. Biggin, M. D., T. J. Gibson, and G. F. Hong. 1983. Buffer gradient gels and ${ }^{35} \mathrm{~S}$ label as an aid to rapid DNA sequence determination. Proc. Natl. Acad. Sci. USA 80:3963-3965.

4. Bové, J. M., P. Carle, M. Garnier, F. Laigret, J. Renaudin, and C. Saillard. 1989. Molecular and cellular biology of spiroplasmas, p. 243-364. In R. F. Whitcomb and J. G. Tully (ed.), The mycoplasmas, vol. 5. Academic Press, Inc., New York.

5. Dams, E., L. Hendriks, Y. Van de Peer, J.-M. Neefs, G. Smits, I. Vandenbempt, and R. De Wachter. 1988. Compilation of small ribosomal subunit RNA sequences. Nucleic Acids Res. Suppl. 16:r87-r173.

6. Devereux, J., P. Haeberli, and O. Smithies. 1984. A comprehensive set of sequence analysis programs for the VAX. Nucleic Acids Res. 12:387-395.

7. Dybvig, K., and T. Alderete. 1988. Transformation of Mycoplasma pulmonis and Mycoplasma hyorhinis: transposition on Tn916 and formation of cointegrate structures. Plasmid 20:3341.

8. Dybvig, K., and G. H. Cassell. 1987. Transposition of grampositive transposon Tn916 in Acholeplasma laidlawii and $M y$ coplasma pulmonis. Science 235:1392-1394.

9. Fitch, W. M., and E. Margoliash. 1987. Construction of phylogenetic trees: a method based on mutational differences as estimated from cytochrome c sequences is of general applicability. Science 155:279-284.

10. Fox, G. E., E. Stackebrandt, R. B. Hespell, J. Gibson, J. Maniloff, T. A. Dyer, R. S. Wolfe, W. E. Balch, R. S. Tanner, L. J. Magrum, L. B. Zablen, R. Blakemore, R. Gupta, L. Bonen, B. J. Lewis, D. A. Stahl, K. R. Luehrsen, N. N. Chen, and C. R. Woese. 1980. The phylogeny of prokaryotes. Science 209:457463.

11. Freitag, J. H. 1964. Interaction and mutual suppression among three strains of aster yellows virus. Virology 24:401-413.

12. Göbel, U. B., G. H. Butler, and E. J. Stanbridge. 1984. Comparative analysis of mycoplasma ribosomal RNA operons. Isr. J. Med. Sci. 20:762-767.

13. Green, C. J., G. C. Stewart, M. A. Hollis, B. S. Vold, and K. F. Bott. 1985. Nucleotide sequence of the Bacillus subtilis ribosomal RNA operon, rrnB. Gene 37:261-266.

14. Henikoff, S. 1984. Unidirectional digestion with exonuclease III creates targeted breakpoints for DNA sequencing. Gene 28:351359.

15. Hori, H., and S. Osawa. 1979. Evolutionary change in 5S RNA secondary structure and a phylogenetic tree of 54 5S RNA species. Proc. Natl. Acad. Sci. USA 76:381-385.

16. Iwami, M., A. Muto, F. Yamao, and S. Osawa. 1984. Nucleotide sequence of the rrnB 16S ribosomal RNA gene from Mycoplasma capricolum. Mol. Gen. Genet. 196:317-322.

17. Kirkpatrick, B. C. 1991 . Mycoplasma-like organisms: plant and invertebrate pathogens, p. 4050-4067. In A. Balows, H. G. Trüper, M. Dworkin, W. Harder, and K. H. Schliefer (ed.), The prokaryotes, 2nd ed. Springer-Verlag Press, New York.

18. Kirkpatrick, B. C., and J. D. Fraser. 1989. Phylogenetic relationships of the Western X-disease mycoplasma-like organism (X-MLO) as established by 16S rRNA sequence. Phytopathology 79:1138.
19. Kirkpatrick, B. C., and J. D. Fraser. 1989. Detection and differentiation of mycoplasma-like organisms using MLO-specific ribosomal RNA oligonucleotide sequences. Phytopathology 79:1206.

20. Kirkpatrick, B. C., and J. D. Fraser. Unpublished data.

21. Kirkpatrick, B. C., D. C. Stenger, T. J. Morris, and A. H. Purcell. 1987. Cloning and detection of DNA from a nonculturable plánt pathogenic mycoplasma-like organism. Science 238: $197-200$.

22. Köllar, A., and E. Seemüller. 1989. Base composition of the DNA of mycoplasma-like organisms associated with various plant diseases. J. Phytopathol. 127:177-186.

23. Kuske, C. R. 1989. Ph.D. thesis. University of California, Davis.

24. Kuske, C. R., and B. C. Kirkpatrick. 1990. Identification and characterization of plasmids from the western aster yellows mycoplasmalike organism. J. Bacteriol. 172:1628-1633.

25. Lim, P.-O., and B. Sears. 1989. 16S rRNA sequence indicates plant-pathogenic "mycoplasma-like organisms" are evolutionarily distinct from animal mycoplasmas. J. Bacteriol. 171:59015906.

26. Loughney, K., E. Lund, and J. E. Dahlberg. 1982. tRNA genes are found between the 16S and 23S rRNA genes in Bacillus subtilis. Nucleic Acids Res. 10:1607-1624.

27. Loughney, K., E. Lund, and J. E. Dahlberg. 1983. Ribosomal precursors of Bacillus subtilis. Nucleic Acids Res. 11:6709 6721.

28. Mahairas, G. G., and S. C. Minion. 1989. Transformation of Mycoplasma pulmonis: demonstration of homologous recombination, introduction of cloned genes, and preliminary description of an integrating shuttle system. J. Bacteriol. 171:17751780 .

29. Maniatis, T., G. F. Fritsch, and J. Sambrook. 1982. Molecular cloning, a laboratory manual. Cold Spring Harbor Laboratory, Cold Spring Harbor, N.Y.

30. Maniloff, J. 1983. Evolution of wall-less prokaryotes. Annu. Rev. Microbiol. 37:477-499.

31. Morgan, E. A., T. Ikemura, and M. Nomura. 1977. Identification of spacer tRNA genes in individual ribosomal RNA transcription units of Escherichia coli. Proc. Natl. Acad. Sci. USA 74:2710-2714.

32. Neimark, H., and B. C. Kirkpatrick. 1990. Isolation and size estimation of whole chromosomes from mycoplasma-like organisms. Phytopathology 80:959.

33. Neimark, H. C., and C. S. Lange. 1990. Pulsed-field electrophoresis indicates full-length mycoplasma chromosomes range widely in size. Nucleic Acids Res. 18:5443-5448.

34. Noller, H. F. 1984. Structure of ribosomal RNA. Annu. Rev. Biochem. 53:119-162.

35. Nomura, M., R. Gourse, and G. Baughman. 1984. Regulation of the synthesis of ribosomes and ribosomal components. Annu. Rev. Biochem. 53:75-117.

36. Olsen, G. J., D. J. Lane, S. J. Giovannoni, and N. R. Pace. 1986. Microbial ecology and evolution: a ribosomal RNA approach. Annu. Rev. Microbiol. 40:337-365.

37. Pyle, L., L. Corcoran, B. G. Cocks, A. D. Bergmann, J. C. Whitley, and L. R. Finch. 1988. Pulsed-field electrophoresis indicates larger than expected sizes for mycoplasma genomes. Nucleic Acids Res. 16:6015-6026.

38. Rasmussen, O. F., J. Frydenberg, and C. Christiansen. 1987. Analysis of the leader and spacer region of the two rRNA operons of Mycoplasma PG50: two tRNA genes are located upstream of rrnA. Mol. Gen. Genet. 208:23-29.

39. Razin, S. 1985. Molecular biology and genetics of mycoplasmas (Mollicutes). Microbiol. Rev. 49:419-455.

40. Razin, S. 1989. Molecular approach to mycoplasma phylogeny, p. 33-69. In R. F. Whitcomb and J. G. Tully (ed.), The mycoplasmas, vol. 5. Academic Press, Inc., New York.

41. Razin, S., M. F. Barile, R. Harasawa, D. Amikam, and G. Glaser. 1983. Characterization of the mycoplasma genome. Yale J. Biol. Med. 56:357-366.

42. Roberts, M. C., and G. E. Kenny. 1987. Conjugal transfer of transposon Tn916 from Streptococcus faecalis to Mycoplasma 
hominis. J. Bacteriol. 169:3836-3839.

43. Rogers, M. J., J. Simmons, R. T. Walker, W. G. Weisburg, C. R. Woese, R. S. Tanner, I. M. Robinson, and J. Maniloff. 1985. Construction of the mycoplasma evolutionary tree from 5S rRNA sequence data. Proc. Natl. Acad. Sci. USA 82:11601164.

44. Rogers, M. J., A. A. Steinmetz, and R. T. Walker. 1986. The nucleotide sequence of a tRNA gene cluster from Spiroplasma melliferum. Nucleic Acids Res. 14:3145.

45. Rosenberg, M., and D. Court. 1979. Regulatory sequences involved in the promotion and termination of RNA transcription. Annu. Rev. Genet. 13:319-353.

46. Sawada, M., A. Muso, M. Iwami, F. Yamao, and S. Osawa. 1984. Organization of ribosomal RNA genes in Mycoplasma capricolum. Mol. Gen. Genet. 196:311-316.

47. Sears, B. B., P.-O. Lim, N. Holland, B. C. Kirkpatrick, and K. L. Klomparens. 1989. Isolation and characterization of DNA from a mycoplasmalike organism. Mol. Plant-Microbe Interact. 2:175-180.

48. Shine, J., and L. Dalgarno. 1974. The $3^{\prime}$-terminal sequence of Escherichia coli $16 \mathrm{~S}$ ribosomal RNA: complementarity to nonsense triplets and ribosome binding sites. Proc. Natl. Acad. Sci. USA 71:1342-1346.

49. Sladek, T. L., and J. Maniloff. 1983. Polyethylene glycoldependent transfection of Acholeplasma laidlawii with mycoplasma virus L2 DNA. J. Bacteriol. 155:734-741.

50. Taschke, C., and R. Herrmann. 1986. Analysis of transcription and processing signals of the 16S-23S rRNA operon of Mycoplasma hyopneumoniae. Mol. Gen. Genet. 205:434-441.

51. Taschke, C., and R. Herrmann. 1988. Analysis of transcription and processing signals in the $5^{\prime}$ regions of the two Mycoplasma capricolum rRNA operons. Mol. Gen. Genet. 212:522-530.
52. Taschke, C., M. Klinkert, J. Wolters, and R. Herrmann. 1986. Organization of the ribosomal RNA genes in Mycoplasma hyopneumoniae: the 5S rRNA gene is separated from the 16S and 23S rRNA genes. Mol. Gen. Genet. 205:428-433.

53. Tully, J. G. 1989. Class Mollicutes: new perspectives from plant and arthropod studies, p. 1-31. In R. F. Whitcomb and J. G. Tully (ed.), The mycoplasmas, vol. 5. Academic Press, Inc., New York.

54. Weisberg, W. G., J. G. Tully, D. L. Rose, J. P. Petzel, H. Oyaizu, D. Yang, L. Mandelco, J. Sechrest, T. G. Lawrence, J. Van Etten, J. Maniloff, and C. R. Woese. 1989. A phylogenetic analysis of the mycoplasmas: basis for their classification. J. Bacteriol. 171:6455-6467.

55. Woese, C. R. 1987. Bacterial evolution. Microbiol. Rev. 51:221271.

56. Woese, C. R., R. Gutell, R. Gupta, and H. Noller. 1983. Detailed analysis of the higher-order structure of $16 \mathrm{~S}$-like ribosomal ribonucleic acids. Microbiol. Rev. 47:621-669.

57. Woese, C. R., J. Maniloff, and L. B. Zablen. 1980. Phylogenetic analysis of the mycoplasmas. Proc. Natl. Acad. Sci. USA 77:494-498.

58. Woese, C. R., E. Stackebrandt, and W. Ludwig. 1985. What are mycoplasmas: the relationship of tempo and mode in bacterial evolution. J. Mol. Evol. 21:305-316.

59. Young, R. A., R. Macklis, and J. A. Steitz. 1979. Sequence of the 16S-23S spacer region in two ribosomal RNA operons of Escherichia coli. J. Biol. Chem. 254:3264-3271.

60. Young, R. A., and J. A. Steitz. 1978. Complementary sequences 1700 nucleotides apart form a ribonuclease III cleavage site in Escherichia coli ribosomal precursor RNA. Proc. Natl. Acad. Sci. USA 75:3593-3597. 